\title{
Induction of Non-Apoptotic Cell Death by Adrenergic Agonists in Human Oral Squamous Cell Carcinoma Cell Lines
}

\author{
SHIGENORI UCHIDA ${ }^{1}$, KATSUE KOBAYASHI ${ }^{2}$, SEIKA OHNO ${ }^{3}$, \\ HIROSHI SAKAGAMI ${ }^{4}$, HIKARU KOHASE ${ }^{1}$ and HIROSHI NAGASAKA ${ }^{5}$ \\ ${ }^{1}$ Division of Dental Anesthesiology, Department of Diagnostic and Therapeutic Sciences, \\ Meikai University School of Dentistry, Saitama, Japan; \\ ${ }^{2}$ Division of Dentistry for Persons with Disabilities, Department of Community Health Sciences, \\ Meikai University School of Dentistry, Saitama, Japan; \\ ${ }^{3}$ Department of Anesthesiology, Saitama Medical University International Medical Center, Saitama, Japan; \\ ${ }^{4}$ Meikai University Research Institute of Odontology (M-RIO), Saitama, Japan; \\ ${ }^{5}$ Department of Anesthesiology, Saitama Medical University, Faculty of Medicine, Moroyama, Japan
}

\begin{abstract}
Background/Aim: Although adrenergic agonists have been used in dental treatments and oral surgery for general anesthesia, their cytotoxicity against human oral malignant and non-malignant cell has not been well- understood. The present study was undertaken to investigate the cytotoxicity of five adrenergic agonists against human oral squamous cell carcinoma (OSCC), glioblastoma, promyelocytic leukemia, and normal oral mesenchymal cells (gingival fibroblast, pulp cell, periodontal ligament fibroblast) and normal epidermal keratinocytes. Materials and Methods: Tumor-specificity (TS) was calculated by the ratio between the mean 50\% cytotoxic concentration against normal cells to that of tumor cells. Internucleosomal DNA fragmentation was detected using agarose gel electrophoresis. Caspase-3 activity was measured by substrate cleavage. Results: Both cytotoxicity and tumorspecificity of adrenergic agonists against OSCC cell lines was in the order of isoprenaline $>$ dexmedetomidine $>$ adrenaline $>$ clonidine and phenylephrine. Isoprenaline and dexmedetomidine did not induce apoptosis markers, such as internucleosomal DNA fragmentation and caspase-3 activation, but induced a smear pattern of DNA fragmentation in OSCC cell lines. Their cytotoxicity was not reduced by pretreatment with autophagy inhibitors, or by adrenoceptors antagonists. Addition
\end{abstract}

This article is freely accessible online.

Correspondence to: Shigenori Uchida, Division of Dental Anesthesiology, Meikai University School of Dentistry, Sakado, Saitama 350-0283, Japan. Tel: +81 492792738, +81 492792758, e-mail: sashichitaru930@dent.meikai.ac.jp, sakagami@dent.meikai.ac.jp

Key Words: Oral squamous carcinoma cell, adrenergic agonists, necrosis, ROS. of superoxide dismutase and catalase significantly reduced the cytotoxicity of isoprenaline, but not that of dexmedetomidine. Conclusion: Isoprenaline and dexmedetomidine induce nonapoptotic cell death by different mechanisms.

Intravenous and local anesthetics are indispensable for dental treatments and oral surgery. Adrenergic agonists, such as dopamine, noradrenaline, adrenaline (biogenic amines) and isoprenaline (synthetic drug) have been used frequently in perioperative treatments (1). Adrenaline ( $\alpha, \beta$-agonist) contracts blood vessels and consequently decreases the bleeding (2), delays the absorption of local anesthetics from the surgical field, and prolongs the anesthetic duration. Also, if adrenaline's vasoconstrictive action is too strong, the nerve fibers become ischemic and may cause hypoesthesia. In clinical practice, excessive administration of adrenaline, in particular following anesthesia in the periodontal ligament, may cause a reduction in pulp blood flow and dry sockets after tooth extraction (3). Adrenaline $(10 \sim 100 \mu \mathrm{g} / \mathrm{ml})$ inhibits the invasion of human oral squamous cell carcinoma (OSCC) cells by raising the intracellular concentration of cAMP (4). However, cytotoxicity of adrenaline against normal cells has not been described. Isoprenaline ( $\beta$-agonist) is used to induce cardiomyopathy, which can be ameliorated by downregulating the expression of proinflammatory cytokines (IL-6, IL-10 and TNF $\alpha$ ) and apoptotic markers (caspase-3 and $\mathrm{Bax}$ ), and up-regulating the anti-apototic protein $\mathrm{Bcl} 2$ (5). Phenylephrine and clonidine are well known $\alpha_{1}$ and $\alpha_{2}$ adrenergic receptor agonists that increase and reduce the blood pressure, respectively $(1,6)$, but as far as we know, their anticancer effects on oral cancer have not been reported yet.

Dexmedetomidine $\left(\alpha_{2}\right.$-adrenoceptor agonist with an imidazole ring) has been approved for sedation in the intensive care unit (ICU) (7), for dental treatments and in oral surgery 
<smiles>CNC[C@H](O)c1ccc(O)c(O)c1</smiles><smiles>CNC[C@H](O)c1cccc(O)c1</smiles>

Phenylephrine

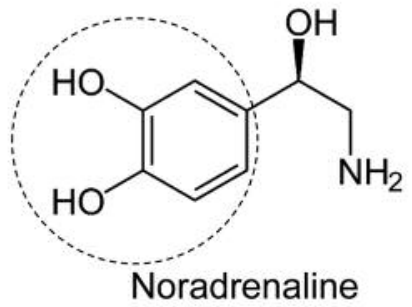<smiles>Clc1cccc(Cl)c1NC1=NCCN1</smiles>

Clonidine<smiles>CC(C)NCC(O)c1ccc(O)c(O)c1</smiles><smiles>Cc1cccc(C(C)c2c[nH]cn2)c1C</smiles>

Dexmedetomidine

Figure 1. Chemical structure of the five adrenergic agonists used: adrenaline, isoprenaline, phenylephrine, clonidine, dexmedetomidine.

(8). Higher concentration of dexmedetomidine induces apoptosis in neutrophils, and then suppresses the superoxide generation (9). On the other hand, dexmedetomidine has demonstrated an anti-apoptotic protective effect on hypoxiainduced neuronal damage (10). A survey of the existing literature has revealed that very little information is available on the antitumoral potential of adrenergic agonists against oral cancer, in comparison to their effect on normal oral cells (11).

In the present study, we investigated the relative cytotoxicity of five adrenergic drugs, two catecholamines (adrenaline, isoprenaline) and three non-catecholamines (phenylephrine, clonidine, dexmedetomidine) (Figure 1) against human oral OSCC cell lines (HSC-2, HSC-3, HSC4), normal mesenchymal oral cells (gingival fibroblast HGF, periodontal ligament fibroblast HPLF, pulp cell HPC), normal epidermal keratinocytes (HEK-a, HEK-n), glioblastoma (U87MG, T98G) and promyelocytic leukemia (HL-60) cells. Isoprenaline and dexmedetomidine, which showed the highest cytotoxicity and tumor-specificity, were further investigated for their apoptosis-inducing activity.

\section{Materials and Methods}

Materials. The following chemicals and reagents were obtained from the indicated companies: RPMI-1640, Dulbecco's modified Eagle medium (DMEM) (Gibco BRL, Grand Island, NY, USA), fetal bovine serum (FBS), 3-(4,5-dimethylthiazol-2yl)-2,5-diphenyltetrazolium bromide (MTT), phenylephrine, 3-methyladenine (3-MA), superoxide dismutase (SOD) (Sigma Chem. Ind., St. Louis, MO, USA), dimethyl sulfoxide (DMSO), NaI, adrenaline, propranolol, yohimbine and catalase (Wako Pure Chemicals, Osaka, Japan), isoprenaline, tetrakis (4-benzoic acid) porphyrin chloride (Mn-TBAP)
(CALBIOCHEM), clonidine (REFERENCE STANDARD), dexmedetomidine (TOCRIS bioscience, Bristol, UK, RNase A, Proteinase K, ethidium bromide, agarose S (NIPPON GENE Co., Ltd, Toyama Japan), DNA molecular marker (Bayou Biolabs, Harahan, CA, USA), 100 mm-plastic dish, 24-well plate and 96-microwell plate (Becton Dickinson, Franklin Lakes, NJ, USA), substrates of caspase3 [DEVD- $p$-nitroanilide ( $p \mathrm{NA})$ ] (MBL, Aichi Prefecture, Japan, HuMedia-KG2 (KURABO, Osaka, Japan), bafilomycin A1 (BAF) (Cosmobio, Tokyo, Japan). Adrenergic agonists were dissolved in DMSO at $100 \mathrm{mM}$ before use, and were diluted in the medium.

Cell culture. HL-60 cells (Riken, Tsukuba, Japan) were cultured at $37^{\circ} \mathrm{C}$ in RPMI-1640 supplemented with $10 \%$ heat-inactivated FBS. Human OSCC cell lines (HSC-2, HSC-3, HSC-4) (provided by Professor Nagumo, Showa University), normal human oral cells, gingival fibroblast (HGF), pulp cells (HPC) and periodontal ligament fibroblast (HPLF) (prepared from periodontal tissues of a 12 year-old patient, according to the guideline of the Intramural Ethic Committee no. A0808) (8), and human glioblastoma cell lines (T98G and U87MG) (provided by Dr. Masataka Iida, Showa University), were cultured in DMEM supplemented with $10 \%$ heatinactivated FBS. Since normal oral cells have a limited lifespan of 43-47 population doubling levels (PDL), they were used at 8-15 PDL (12). Human epidermal keratinocytes (HEK-a, HEK-n) (purchased from Kurabo, Osaka, Japan) were cultured in HuMediaKG2 supplemented with insulin, human recombinant epidermal growth factor (hEGF), hydrocortisone, gentamicin, amphotericin B and bovine pituitary gland extract (BPE), according to the manufacturer's instruction. Control cells inoculated in the same rows of the 96-microwell plates were treated with the same amounts of DMSO and the cell damage induced by DMSO was subtracted from that induced by the test agents.

Cytotoxic activity assay. All cells were inoculated at a concentration of $3 \times 10^{3}$ cells/well in 96-microwell plate (Becton Dickinson Labware, 


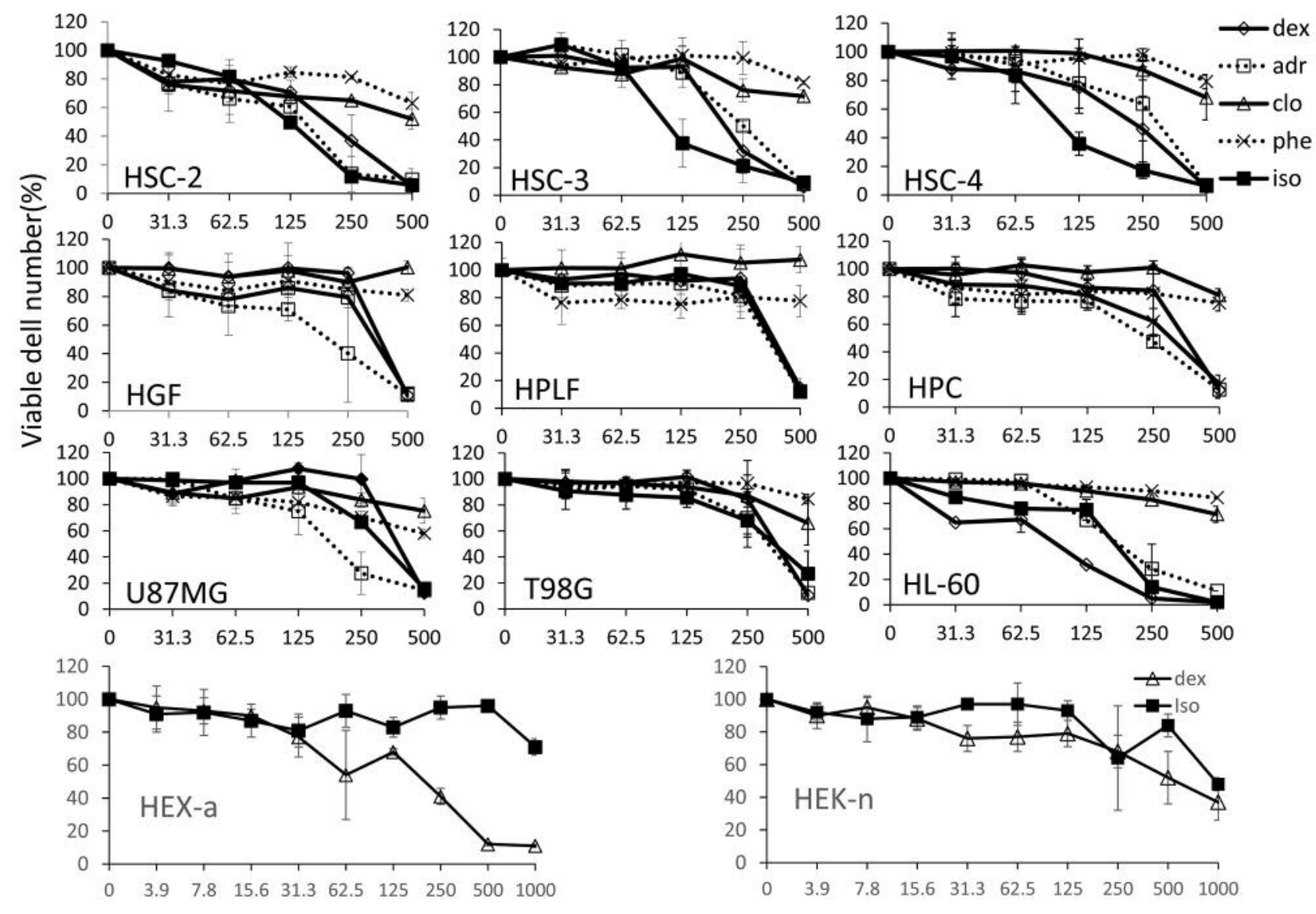

Concentration $(\mu \mathrm{M})$

Figure 2. Cytotoxic activity of five adrenergic agonists against human normal and tumor cells. Cells were treated for 48 hours without (control), or with the indicated concentrations of the five adrenergic agonists. The viable cell number was then determined by the MTT method and was expressed as $\%$ of the control. Each value represents the mean $\pm S . D$. from 3 or 4 independent experiments.

NJ, USA), unless otherwise stated. After 48 hours, the medium was removed by suction with an aspirator, and was replaced with $0.1 \mathrm{ml}$ of fresh medium containing different concentrations of the test compounds. The same concentrations of vehicle (DMSO) were added to control cells. The cells were incubated for another 48 hours, and the relative viable cell number was then determined by the MTT method (7). In brief, the cells were washed once with phosphatebuffered saline without $\mathrm{Ca}^{2+}$ and $\mathrm{Mg}^{2+}[\mathrm{PBS}(-)]$, and were replenished with fresh culture medium containing $0.2 \mathrm{mg} / \mathrm{ml}$ MTT. Following incubation for 4 hours, cells were lysed with $0.1 \mathrm{ml}$ of DMSO, and the absorbance at $540 \mathrm{~nm}$ of the cell lysate was determined using a microplate reader (Biochromatic Labsystem, Helsinki, Finland). From the dose-response curve, the $50 \%$ cytotoxic concentration $\left(\mathrm{CC}_{50}\right)$ was determined.

Calculation of tumor-specificity. Tumor-specificity (TS) of each sample was calculated using the following equations:

(1) $\mathrm{TS}_{\mathrm{M}}=$ mean $\mathrm{CC}_{50}$ against three human oral normal mesenchymal cells (HGF, HPLF, HPC)/mean $\mathrm{CC}_{50}$ against three human OSCC cell lines (HSC-2, HSC-3, HSC-4).
(2) $\mathrm{TS}_{\mathrm{E}}=$ mean $\mathrm{CC}_{50}$ against two human normal epidermal cells (HEK-a, HEK-n)/mean $\mathrm{CC}_{50}$ against three OSCC cell lines (HSC-2, HSC-3, HSC-4).

Assay for DNA fragmentation. Cells treated with isoprenaline and dexmedetomidine were lysed by lysate buffer [50 mM Tris- $\mathrm{HCl}$ (pH 7.8), $10 \mathrm{mM}$ EDTA, $0.5 \%$ (w/v) sodium $N$-lauroylsalcosinate]. The lysate was incubated with $0.4 \mathrm{mg} / \mathrm{ml}$ RNase A (Takara Bio Inc., Shiga, Japan) and $0.8 \mathrm{mg} / \mathrm{ml}$ proteinase K (Takara Bio Inc.) for 1-2 hours at $50^{\circ} \mathrm{C}$, and was then mixed with $50 \mu \mathrm{NaI}$ solution (7.6 M NaI, $20 \mathrm{mM}$ EDTA-2Na, $40 \mathrm{mM}$ Tris-HCl, $\mathrm{pH} \mathrm{8.0),} \mathrm{and}$ $100 \mu \mathrm{l}$ of ethanol. Following centrifugation for 20 minutes at $20,000 \times g, 4{ }^{\circ} \mathrm{C}$, the precipitate was washed with $1 \mathrm{ml}$ of $70 \%$ ethanol and was dissolved in TE buffer $(10 \mathrm{mM}$ Tris-HCl, $1 \mathrm{mM}$ EDTA, pH 3-5). The sample (10-20 $\mu$ l) was then applied to $2 \%$ agarose gel electrophoresis in TBE buffer ( $89 \mathrm{mM}$ Tris- $\mathrm{HCl}, 89$ $\mathrm{mM}$ boric acid, $2 \mathrm{mM}$ EDTA, pH 8.0) (13). The DNA molecular marker (Takara Bio Inc.) and the oligonucleosomal DNA fragments from HL-60 cells induced to apoptosis by ultraviolet (UV) irradiation were used for calibration. The DNA fragmentation pattern was examined in photographs taken under UV illumination. 
Table I. Cytotoxic activity of five adrenergic agonists against human normal and tumor cells. The CC $C_{50}$ values were calculated from the doseresponse curve in Figure 2. Each value represents mean $\pm S . D$. from 3 or 4 independent experiments. Log P value was cited from Chem Spider (http://www.chemspider.com/Chemical-Structure).

\begin{tabular}{|c|c|c|c|c|c|}
\hline & \multicolumn{5}{|c|}{$\mathrm{CC}_{50}(\mu \mathrm{M})$} \\
\hline & \multicolumn{3}{|c|}{ Catecholamines } & \multicolumn{2}{|c|}{ Non-catecholamines } \\
\hline & Dexmedetomidine & Adrenaline & Isoprenaline & Phenylephrine & Clonidine \\
\hline Lop P (membrane permeability) & 3.1 & -0.632 & 0.25 & -0.03 & 1.41 \\
\hline \multicolumn{6}{|l|}{ Human normal oral mesenchymal cells } \\
\hline HGF & $385.3 \pm 10$ & $210.4 \pm 91.2$ & $359.3 \pm 16.1$ & $>500$ & $>500$ \\
\hline HPC & $369.5 \pm 47.8$ & $238.6 \pm 15.2$ & $316.3 \pm 34.8$ & $>500$ & $>500$ \\
\hline HPLF & $388.4 \pm 50$ & $363.3 \pm 52.1$ & $376.1 \pm 10.8$ & $>500$ & $>500$ \\
\hline \multicolumn{6}{|l|}{ Human epidermal keratinocytes } \\
\hline HEK-a & 205.4 & & $>1000$ & & \\
\hline HEK-n & 569 & & 959.5 & & \\
\hline \multicolumn{6}{|l|}{ Human OSCC cell lines } \\
\hline HSC-2 & $163.5 \pm 81.7$ & $153.5 \pm 38.2$ & $65.5 \pm 35.2$ & $>500$ & $>500$ \\
\hline HSC-3 & $213.1 \pm 56.4$ & $252 \pm 13.3$ & $111.1 \pm 16.4$ & $>500$ & $>500$ \\
\hline HSC-4 & $170.8 \pm 6.6$ & $310.3 \pm 94.7$ & $115.5 \pm 79.8$ & $>500$ & $>500$ \\
\hline \multicolumn{6}{|l|}{ Human glioblastoma cell lines } \\
\hline $\mathrm{T} 98 \mathrm{G}$ & $366.9 \pm 76.8$ & $336.6 \pm 73.3$ & $359.8 \pm 94.5$ & $>500$ & $>500$ \\
\hline U87MG & $392.4 \pm 28.9$ & $190.8 \pm 48.1$ & $331.8 \pm 55.3$ & $>500$ & $>500$ \\
\hline \multicolumn{6}{|l|}{ Human promyelocyte leukemic cell line } \\
\hline HL-60 & $92.8 \pm 3.5$ & $180 \pm 54.5$ & $163 \pm 37.9$ & $>500$ & $>500$ \\
\hline \multicolumn{6}{|l|}{ Tumor-specificity (TS) } \\
\hline $\mathrm{TS}_{\mathrm{M}}($ Mesenchymal cells vs. OSCC) & 2.1 & 1.1 & 3.6 & 1.0 & 1.0 \\
\hline $\mathrm{TS}_{\mathrm{E}}($ Epithelial cells $v s$. OSCC $)$ & 2.1 & & 10.1 & & \\
\hline
\end{tabular}

Assay for caspase activation. Cells treated with isoprenaline and dexmedetomidine were washed with PBS (-) and lysed in lysis solution (MBL, Nagoya, Japan). After cells stood for 10 minutes on ice, they were centrifuged for 5 minutes at $10,000 \times g$ and the supernatant was collected. The lysate $(50 \mu \mathrm{l}$, equivalent to $100 \mu \mathrm{g}$ protein) was mixed with $50 \mu \mathrm{l} 2 \times$ reaction buffer (MBL) containing substrates for caspase-3 (DEVD-pNA). Following incubation for 4 hours at $37^{\circ} \mathrm{C}$, the absorbance at $405 \mathrm{~nm}$ of the liberated chromophore pNA was measured by a microplate reader (Labsystems Multiskan, Biochromatic Labsystem, Osaka, Japan) attached to a Star DOT Matrix printer JL-10 (9). Apoptotic cells (positive control) were prepared by exposing human promyelocytic leukemic HL-60 cells to 1-minute UV irradiation (14).

Statistical analysis. Each value in the graph of the cell proliferation activity shows the mean and standard deviation from three to four independent experiments. Each experiment was performed at least in triplicate to confirm the reproducibility of the result. For significant differences between the two groups we used Student's $t$ test and a value of $p<0.05$ was considered significant.

\section{Results}

Cytotoxicity of adrenergic agonists. Isoprenaline, dexmedetomidine and adrenaline reduced the viable cell number of human oral squamous cell carcinoma (OSCC) cell lines (HSC-2, HSC-3, HSC-4), human normal oral mesenchymal cells (HGF, HPLF, HPC), human glioblastoma (U87MG, T98G) and human promyelocytic leukemia cells (HL-60) in a dose-dependent manner (Figure 2). Among five adrenergic agonists, isoprenaline showed the highest cytotoxicity against OSCC cells $\left(\mathrm{CC}_{50}=65.5-115.5 \mu \mathrm{M}\right)$, followed by dexmedetomidine $\left(\mathrm{CC}_{50}=163.5-213.1 \mu \mathrm{M}\right)$ and adrenaline $\left(\mathrm{CC}_{50}=153.5-310.3 \mu \mathrm{M}\right)$. The cytotoxicity of clonidine and phenylephrine was much less $\left(\mathrm{CC}_{50}>500 \mu \mathrm{M}\right)$.

Isoprenaline showed the highest tumor-specificity $\left(\mathrm{TS}_{\mathrm{M}}=3.60\right)$, when determined with OSCC cells and mesenchymal normal oral cells, followed by dexmedetomidine $\left(\mathrm{TS}_{\mathrm{M}}=2.1\right)$, adrenaline $\left(\mathrm{TS}_{\mathrm{M}}=1.1\right)$, clonidine and phenylephrine $\left(\mathrm{TS}_{\mathrm{M}}=1.0\right)$ (Table $\left.\mathrm{I}\right)$. Isoprenaline and dexmedetomidine also showed comparable or slightly higher tumor-specificity $\left(\mathrm{TS}_{\mathrm{E}}=10.1\right.$ and 2.12 , respectively), when determined with OSCC cell lines and normal epidermal keratinocytes (HEK-a, HEK-n).

Among eleven human cell lines, the human promyelocytic leukemic cell line HL-60 showed the highest sensitivity to isoprenaline and dexmedetomidine $\left(\mathrm{CC}_{50}=92.8-163.0 \mu \mathrm{M}\right)$, followed by OSCC $\left(\mathrm{CC}_{50}=65.5-213.1 \mu \mathrm{M}\right)$, mesenchymal normal oral cells $\left(\mathrm{CC}_{50}=316.3-388.4 \mu \mathrm{M}\right)$, glioblastoma $\left(\mathrm{CC}_{50}=331.8-392.4 \mu \mathrm{M}\right)$ and epidermal keratinocytes $\left(\mathrm{CC}_{50}=205.4->1000 \mu \mathrm{M}\right)$ (Table I). Since cytotoxicity of 

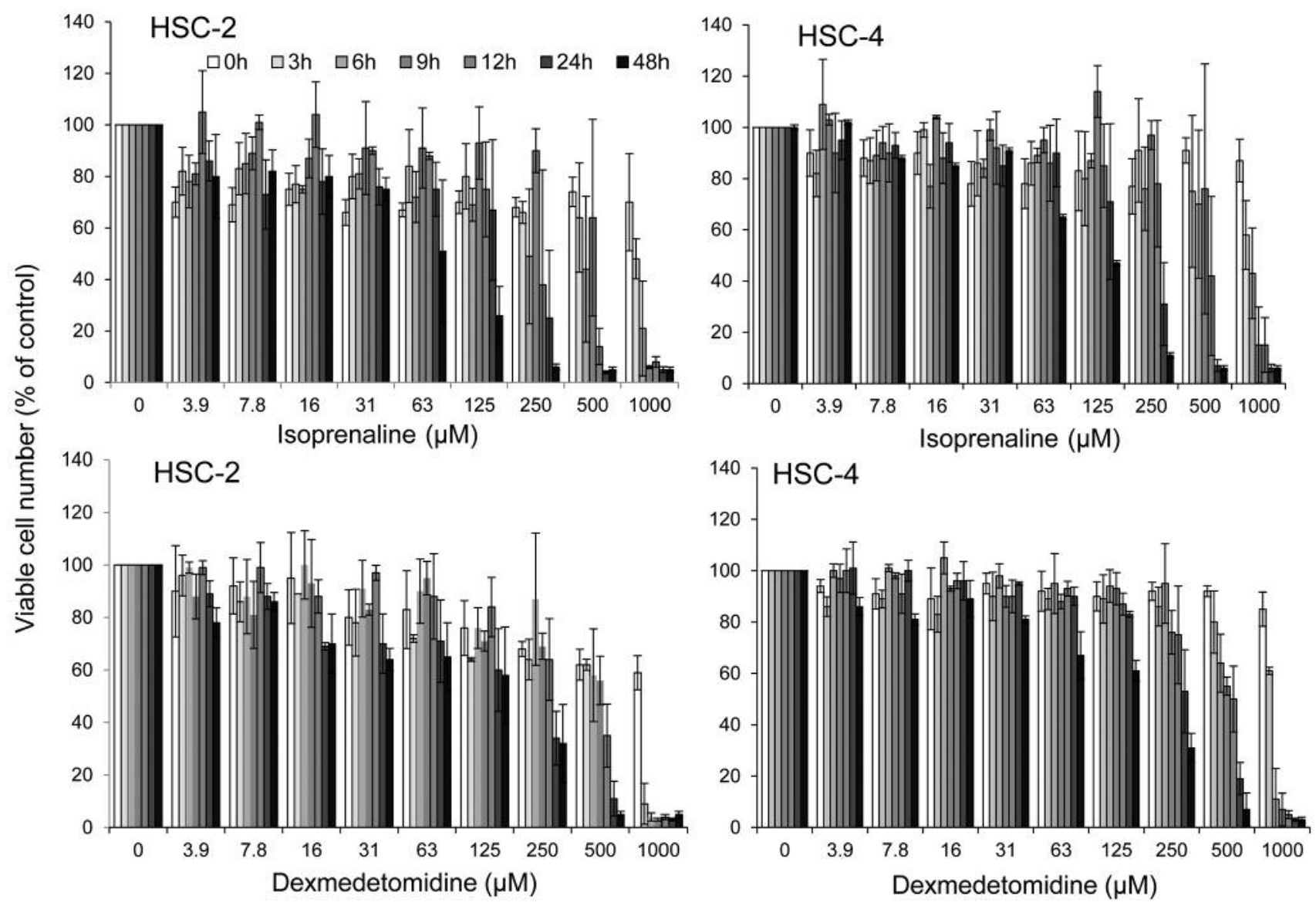

Figure 3. Effect of treatment time of isoprenaline or dexmedetomidine on cytotoxicity induction in HSC-2 and HSC-4 cells. Cells were treated for the indicated times without (control), or with the indicated concentrations of isoprenaline or dexmedetomidine. The viable cell number was then determined by the MTT method, and it was expressed as \% of the control. Each value represents the mean $\pm S . D$. from 3 independent experiments.

isoprenaline and dexmedetomidine was augmented with incubation time, reaching a plateau level at 24 hours, the following experiments were performed at 6 and 24 hours following treatment (Figure 3).

Induction of non-apoptotic cell death. When human promyelocytic leukemic HL-60 cells were treated with isoprenaline or dexmedetomidine, internucleosomal DNA fragmentation, a biochemical hallmark of apoptosis, was induced. This fragmented DNA was used as a positive control. On the other hand, isoprenaline and dexmedetomidine failed to induce internucleosomal DNA fragmentation in human oral squamous cell carcinoma cell lines (HSC-2, HSC-4), but produced a smear pattern of DNA fragmentation 24 hours later (Figure 4), suggesting a possible induction of necrotic cell death.

Isoprenaline (50-400 $\mu \mathrm{M})$ and dexmedetomidine (100$800 \mu \mathrm{M})$ did not increase, but rather slightly reduced caspase- 3 activity at 6 hours $(* p<0.05)$ (Figures $5 \mathrm{~A}$ and $5 \mathrm{~B}$, respectively). At 24 hours, caspase- 3 was activated, but to a much lower extent compared to what we observed in the apoptotic cells (UV-irradiated HL-60 cells) $(* p<0.05)$ (Figure 5C).

Pretreatment of HSC-2 and HSC-4 cells with autophagy inhibitors at two different concentrations, such as 3methyladenine (5 and $10 \mathrm{mM}$ ) or bafilomycin A1 (200 nM and $1 \mu \mathrm{M}$ ) failed to inhibit the isoprenaline or dexmedetomidine-induced cell death (Figure 6), reducing the possibility of autophagy induction by these drugs.

Effect of adrenergic receptor blockers. We next investigated the possibility of involvement of $\alpha_{2}$-receptor in the cell death induction by isoprenaline and dexmedetomidine, using propranolol (non-specific $\beta_{1}, \beta_{2}$-blocker) and yohimbine $\left(\alpha_{2^{-}}\right.$ blocker). We found that pretreatment with propranolol and yohimbine up to $63 \mu \mathrm{M}$ did not affect the growth of cells, if the pretreatment time did not exceed 1 hour (Figures 7A and $7 \mathrm{~B}$, respectively). We found that cell death induction by 


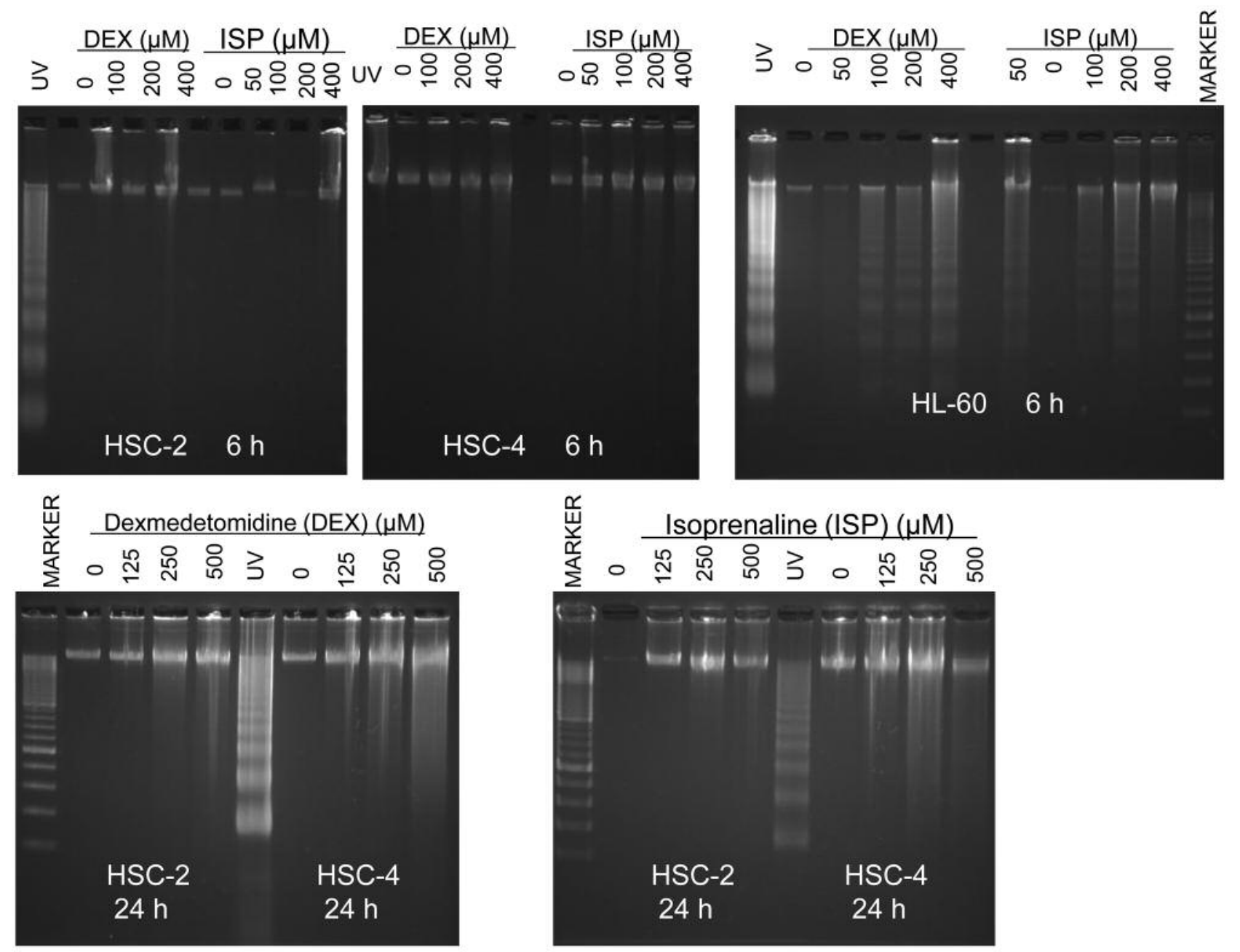

Figure 4. Effect of isoprenaline and dexmedetomidine on DNA fragmentation in HL-60, HSC-2 or HSC-4 cells. HL-60, HSC-2, or HSC-4 cells were incubated for 6 or $24 \mathrm{~h}$ without (control) or with the indicated concentrations of isoprenaline and dexmedetomidine. DNA was then extracted and subjected to agarose gel electrophoresis. UV: DNA from apoptotic HL-60 cells induced by UV irradiation.

isoprenaline was not affected by propranolol, reducing the possibility of the involvement of the $\beta$-receptor (Figure 7C). Likewise, cell death induction by dexmedetomidine was not affected by yohimbine, reducing the possibility of the involvement of the $\alpha_{2}$-receptor (Figure 7D).

Involvement of ROS. It has been reported that catecholamines, such as adrenaline, noradrenaline and isoprenaline (Figure 1) induce cell death by producing reactive oxygen species (ROS) (15). We investigated whether the addition of superoxide dismutase (SOD) that degrades superoxide anion $\left(\mathrm{O}_{2}{ }^{-}\right)$, as well as of catalase that degrades hydrogen peroxide, reduce the cytotoxicity induced by adrenergic agonists. The addition of SOD and catalase (both at 300 units $/ \mathrm{ml}$ ) significantly reduced the cytotoxicity induced by adrenaline (Figure $8 \mathrm{~A}$ ) and isoprenaline (Figure $8 \mathrm{~B})(* p<0.05)$, but not the cytotoxicity induced by dexmedetomidine (Figure 8C). Furthermore, cytotoxicity of dexmedetomidine was not inhibited by Mn-TBAP (10 $\mu \mathrm{M})$ that can penetrate cells (Figure 8D). These data suggest that the generation of ROS is involved in the cytotoxicity induction by catecholamines, such as adrenaline and isoprenaline, but not by non-catecholamines, such as dexmedetomidine.

\section{Discussion}

At present, the vasoconstrictor adrenaline is widely used in Japan at a concentration of $12.5 \mu \mathrm{g} / \mathrm{ml}(68.1 \mu \mathrm{M})$, for balancing the anesthetic effect and the safety during the dental 


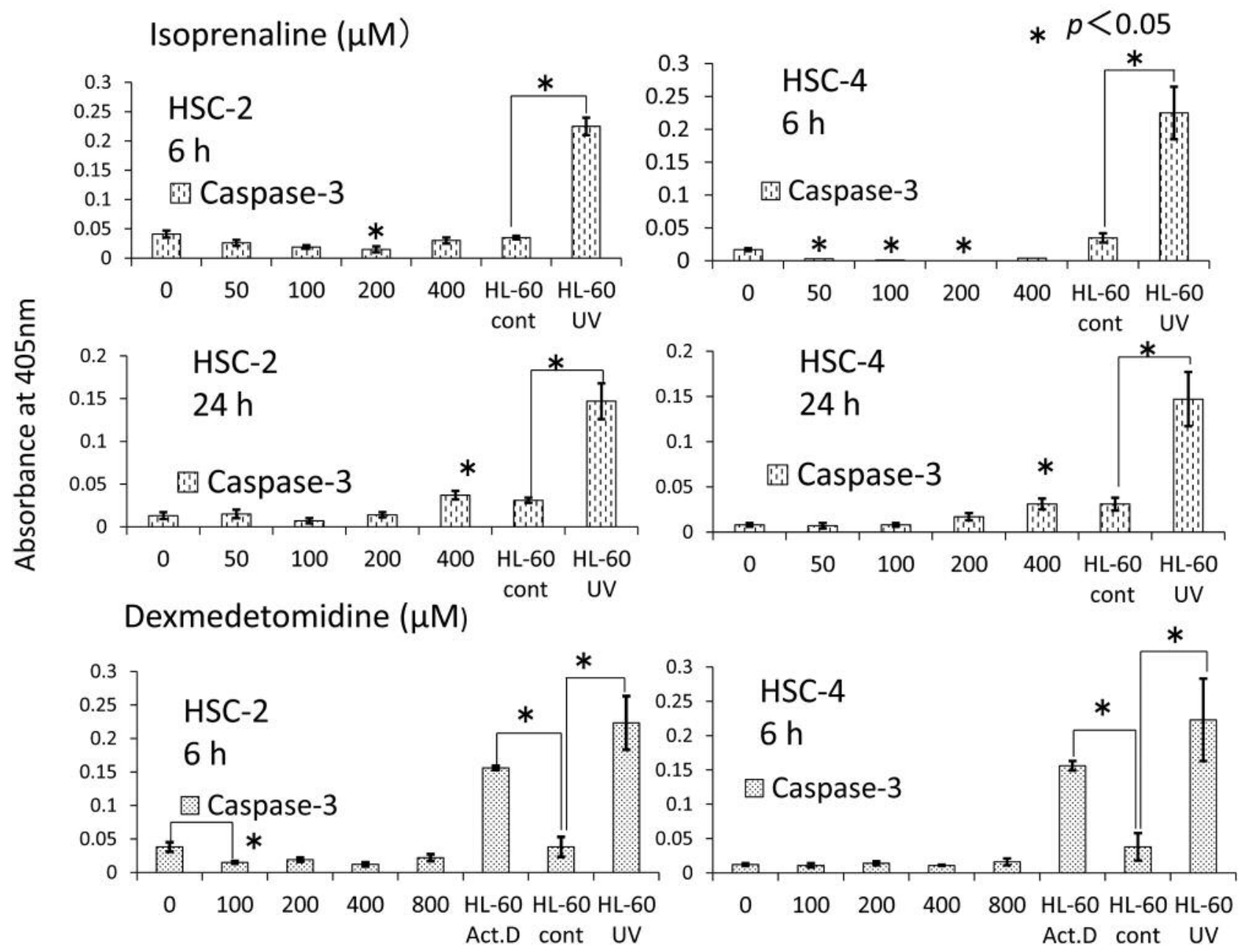

Figure 5. Effect of isoprenaline and dexmedetomidine on caspase-3 activity in HSC-2 and HSC-4 cells. Cells were incubated for $24 \mathrm{~h}$ without (control), or with the indicated concentrations of isoprenaline or dexmedetomidine and then assessed for caspase-3 activity (expressed as $405 \mathrm{~nm}$ of cleaved product for each substrate). Data are expressed as a mean $\pm S . D$. *indicates a significant difference from the HL-60 control value ( $p<0.05)$. UV: HL-60 cells were exposed to 1 min UV irradiation.

injection cartridge formulation (16). The use of lidocaine $2 \%$ with a higher adrenalin concentration of $1: 80,000$ can lead to significant hemodynamic and electrocardiographic changes in perioperative period (17). The $\alpha_{2}$ adrenergic agonist dexmedetomidine stimulates the $\alpha_{2}$ receptor of the locus coeruleus and shows a sedative effect when the plasma concentration is adjusted to $0.3-1.25 \mathrm{ng} / \mathrm{ml}(10 \mathrm{nM})$. Dexmedetomidine is continuously administered intravenously at a dose rate of $6 \mu \mathrm{g} / \mathrm{kg} / \mathrm{h}$ for $10 \mathrm{~min}$ and is then maintained at $0.2-0.7 \mu \mathrm{g} / \mathrm{kg} / \mathrm{h}$, to exert sedation in the intensive care unit (18). The present study demonstrated that phenylephrine $\left(\alpha_{1}\right.$ agonist) and clonidine ( $\alpha_{2}$ agonist) showed very weak cytotoxicity against both oral normal cells and OSCC cells (Table I). Since many drugs have been reported to exhibit biphasic actions (hormesis effect) (19), it is necessary to investigate the possibility of cell growth promotion at a low concentration as well as cytotoxicity at a high concentration.

The present study demonstrated that among five adrenergic agonists, isoprenaline showed the highest cytotoxicity and tumor-specificity between OSCC and mesenchymal normal cells as well as between OSCC and epithelial normal cells. It has been reported that cytotoxicity increases with an increasing octanol/water partition coefficient ( $\log \mathrm{P})$, an index of hydrophobicity, and the cytotoxicity generally can reach a maximum value at $\log \mathrm{P}$ of around $3(20,21)$. In this study, isoprenaline with low hydrophobicity $(\log p=0.25)$ showed higher toxicity compared to dexmedetomidine with high hydrophobicity ( $\log \mathrm{p}=3.10)$ (Table I), suggesting no correlation between cytotoxicity of adrenoceptor agonists and membrane permeability. 


\section{Pretreatment with autophagy inhibitors: $24 \mathrm{~h}$}
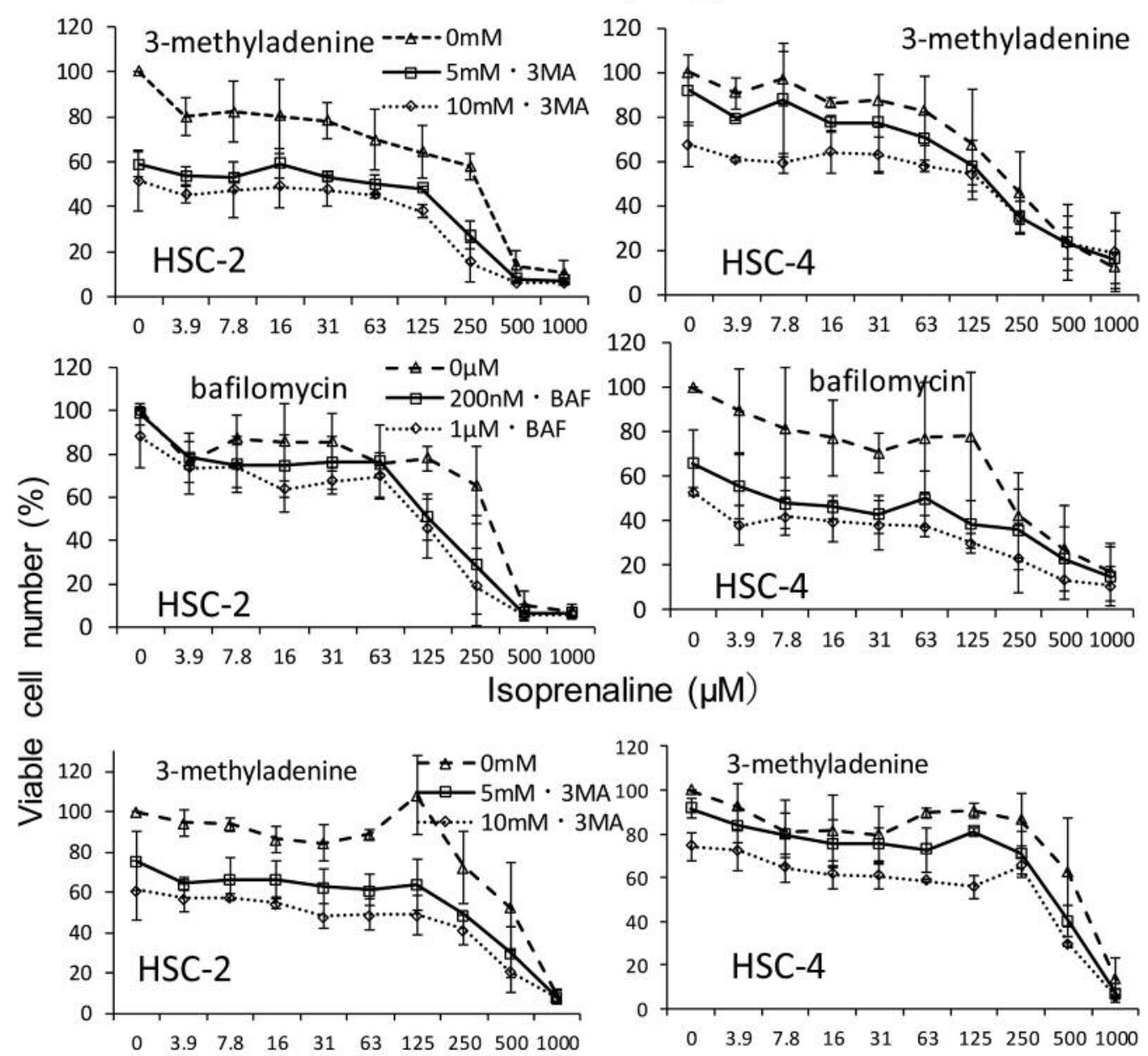

aline $(\mu \mathrm{M})$
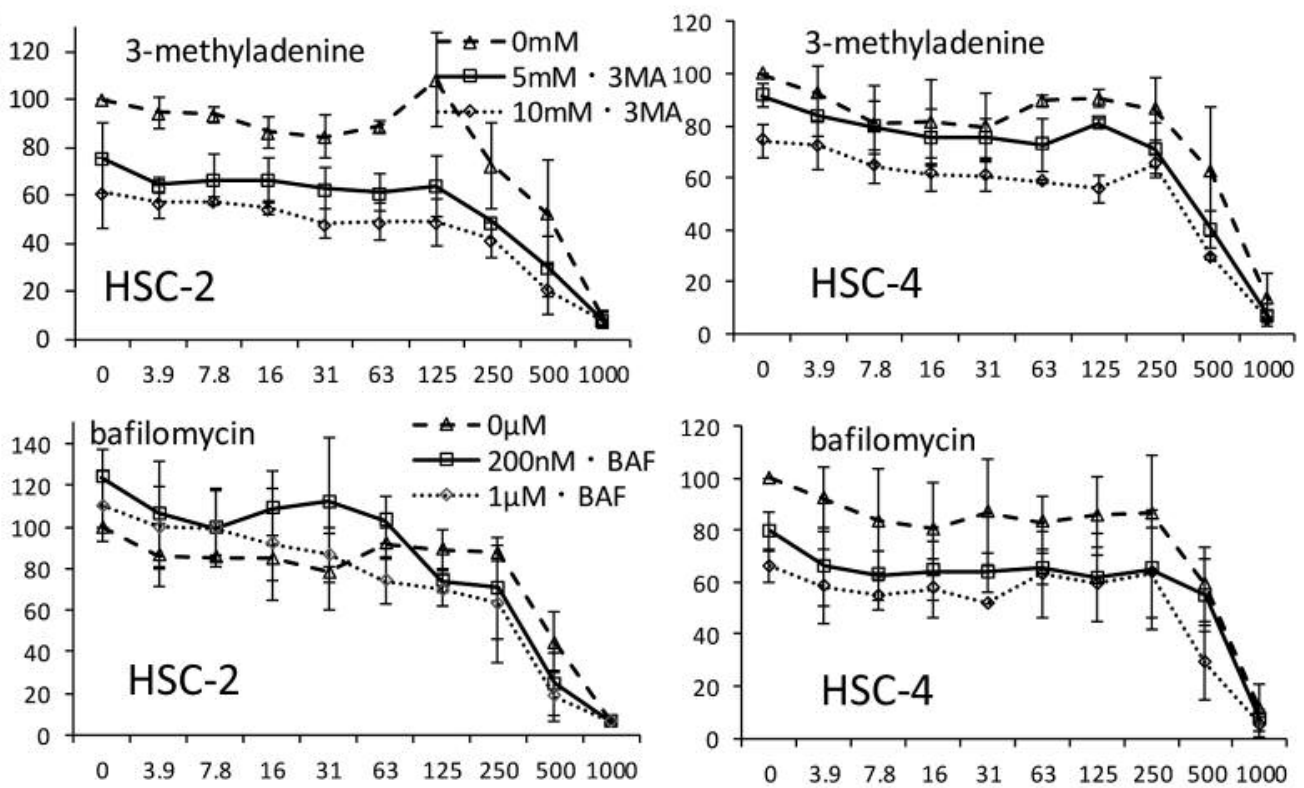

\section{Dexmedetomidine $(\mu \mathrm{M})$}

Figure 6. Effect of autophagy inhibitors (3-MA, BAF) on isoprenaline or dexmedetomidine-induced cytotoxicity against HSC-2 and HSC-4 cells. $H S C-2$ or HSC-4 cells were pretreated for $1 \mathrm{~h}$ with the indicated concentrations of autophagy inhibitors, and were then incubated for $48 \mathrm{~h}$ without (control), or with the indicated concentrations of isoprenaline or dexmedetomidine. The viable cell number was then determined by the MTT method, and was expressed as \% of the control. Each value represents a mean \pm S.D. from 3 or 4independent experiments.

Next, we investigated the type of cell death induced in OSCC cells by isoprenaline and dexmedetomidine. There are many types of cell death, such as intrinsic and extrinsic apoptosis, oncosis, necroptosis, parthanatos, ferroptosis, sarmoptosis, autophagic cell death, autosis, autolysis, paraptosis, pyroptosis, phagoptosis, and mitochondrial permeability transition (22). Judging from our observation that: i) isoprenaline induced smear pattern of DNA fragmentation (23) without inducing apoptosis 

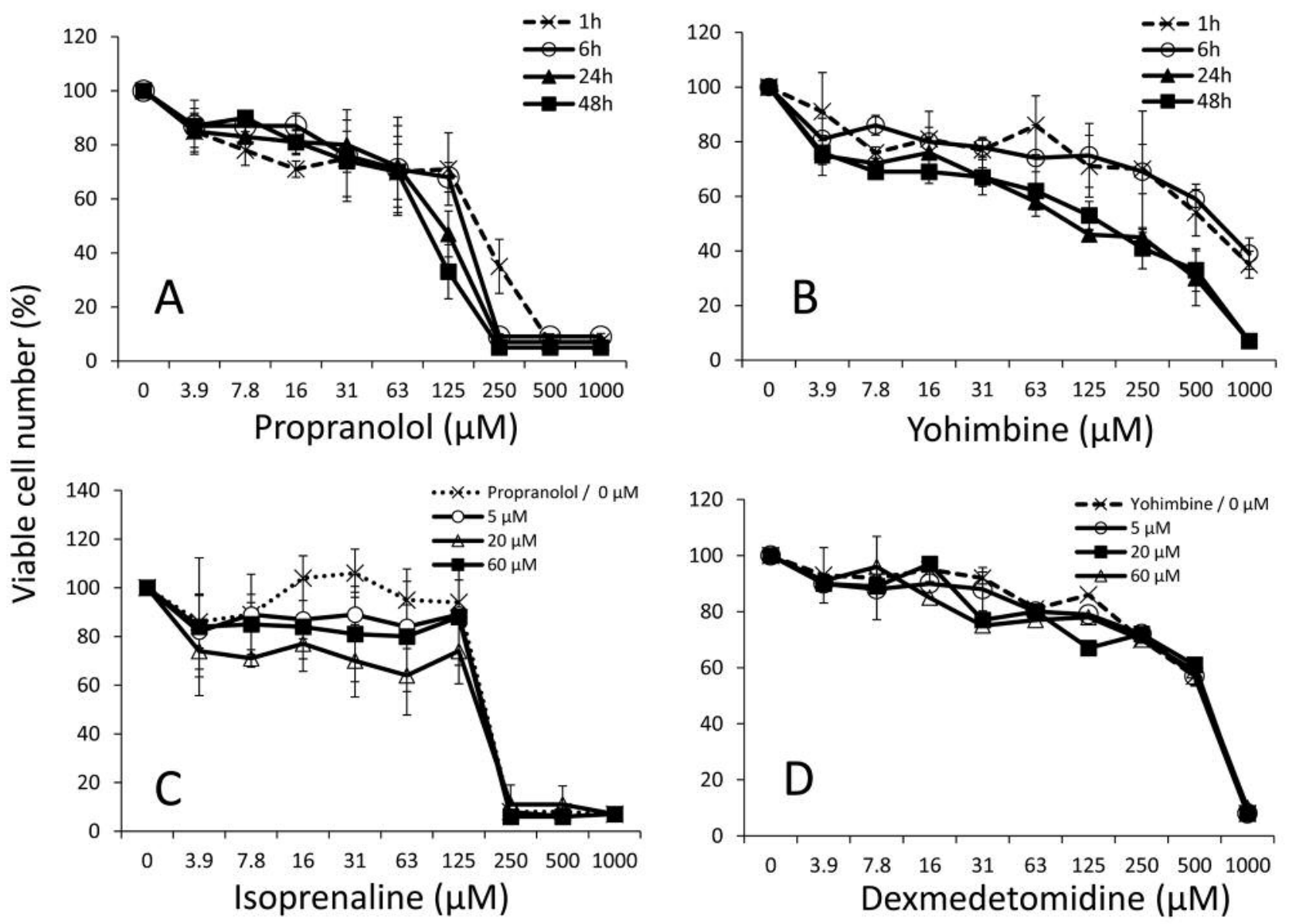

Figure 7. Effect of adrenoreceptors antagonists on isoprenaline and dexmedetomidine-induced cytotoxicity. In order to determine the pretreatment time of propranolol and yohimbine, HSC-2 cells were pretreated for 1, 6, 24 or $48 \mathrm{~h}$ with the indicated concentrations of propranolol (A) and yohimbine (B). Viable cell number was then determined in triplicates by the MTT method, and it was expressed as \% of the control. Each value represents a mean \pm S.D. from 3 or 4 independent experiments. Next, HSC-2 cells were pretreated for $1 \mathrm{~h}$ with the indicated concentrations of isoprenaline $(C)$ and dexmedetomidine $(D)$, and were then incubated for $48 \mathrm{~h}$ without (control), or with the indicated concentrations of isoprenaline or dexmedetomidine. The viable cell number was then determined as described above.

markers (internucleosomal DNA fragmentation, caspase-3 activation) and (ii) the cytotoxicity of isoprenaline was not affected by autophagy inhibitors (3-methyladenine, bafilomycin), it seems that OSCC cells suffered necrotic cell death rather than apoptosis. Further study is required to investigate the possibility of the involvement of necrotic cell death, such as pyroptosis and necroptosis, in which the activation of caspase-1, IL-1 $\beta$ and IL18 pathways is involved (24).

There are reports (25) that the $\beta_{2}$ receptor is expressed in human oral squamous cell carcinoma cells and plays an important role in metastasis, but the association with cytotoxicity is unknown. We found that the cell death induction by isoprenaline was not affected by propranolol, reducing the possibility of the involvement of the $\beta$-receptor (Figure 7C). The cell death induction by dexmedetomidine was also not affected by yohimbine, reducing the possibility of the involvement of the $\alpha_{2}$-receptor (Figure 7D).
Catecholamines, such as dopamine, have been reported to produce hydrogen peroxide $\left(\mathrm{H}_{2} \mathrm{O}_{2}\right)$ (15). Therefore, we examined whether there is a correlation between cytotoxicity and ROS generation ability. We found that the cytotoxicity of isoprenaline and adrenaline, having catechol ring was suppressed by SOD and catalase, suggesting the involvement of ROS generation in the cell death induction. In contrast, the cytotoxicity of dexmedetomidine without catechol backbone did not change even when SOD and catalase were added. We considered that highly hydrophobic dexmedeto-midine, but neither SOD nor catalase pass through the cell membrane and acts inside the cell. However, pretreatment with Mn-TBAP that scavenges intracellular $\mathrm{O}_{2}^{-}$again did not inhibit the injury of dexmedetomidine, suggesting the possibility that ROS may not be involved in the cell death induction. These results suggest that there is a difference in the mechanism of cell death induction between isoprenaline and dexmedetomidine. 


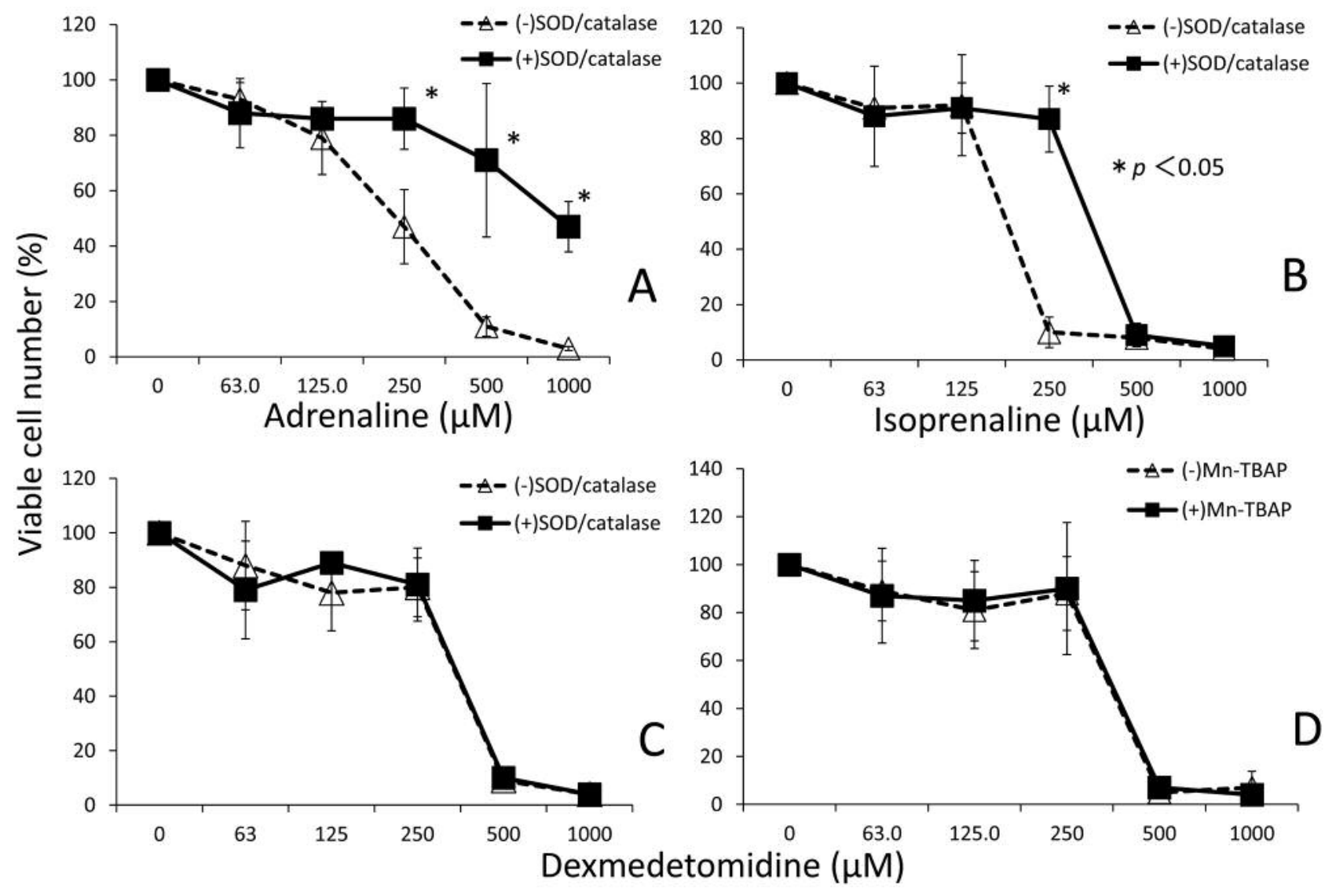

Figure 8. Effect of SOD plus catalase or Mn-TBAP on the cytotoxicity of adrenaline, isoprenaline, dexmedetomidine. HSC-2 cells were incubated for $48 \mathrm{~h}$ without (control), or with the indicated concentrations of adrenaline $(A)$, isoprenaline $(B)$, or dexmedetomidine $(C, D)$ in the presence or absence of SOD plus catalase (300 units/ml each) or Mn-TBAP $(10 \mu M)$. The viable cell number was then determined by the MTT method and was expressed as \% of the control. Each value represents a mean $\pm S . D$. from 3 or 4 independent experiments.

It has been reported that physiological stress levels of norepinephrine and isoproterenol $(10 \mu \mathrm{M})$ at $1 \mathrm{~h}$ elicit the most robust IL-6 increase in secretion from the OSCC cell lines (SCC9 and SCC25). These effects can be blocked by the $\beta$-adrenergic antagonist propranolol, supporting a role for $\beta$ adrenergic receptors in IL-6 secretion (26). This phenomenon observed at a lower concentration of isoproterenol is quite different from that at a higher concentration that is not mediated via $\beta$-adrenergic receptors (Figure 7).

In conclusion, the present study suggests that isoprenaline and dexmedetomidine induce non-apoptotic cell death by distinct mechanisms. Since their $\mathrm{CC}_{50}$ values were much higher than their clinical concentration, combination of other antitumor agents may be necessary for their effective clinical application.

\section{Conflicts of Interest}

The Authors wish to confirm that there are no known conflicts of interest associated with this publication and there has been no significant financial support for this work that could have influenced its outcome.

\section{Authors' Contributions}

HS designed the study and wrote the draft of the manuscript. SU conducted all the experiments with the help of KK and SO. HN and HK supervised the overall study and revised the manuscript.

\section{Acknowledgements}

The Authors thank Prof. Osamu Amano, Prof. Akito Tomomura, Prof. Hasegawa and Dr. Masamichi Tajima, Meikai University School of Dentistry for their valuable comments.

\section{References}

1 Paraskos JA and Orqulota AA: Cardiopulmonary Resuscitation. In: Manual of intensive care medicine 5th edit. Philadelphia, Lippincott Williams \& Wilkins, pp. 197-199, 2008.

2 Kwon S and Sevick-Muraca EM: Effect of lidocaine with and without epinephrine on lymphatic contractile activity in mice in vivo. J Anesth 30(6): 1091-1094, 2016. PMID: 27730311. DOI: $10.1007 / \mathrm{s} 00540-016-2260-8$ 
3 Tsirlis AT, Iakovidis DP and Parissis NA: Dry socket: frequency of occurrence after intraligamentary anesthesia. Quintessence Int 23(8): 575-577, 1992. PMID: 1410263.

4 Yamanaka Y, Mammoto T, Kirita T, Mukai M, Mashimo T, Sugimura M, Kishi $\mathrm{Y}$ and Nakamura H: Epinephrine inhibits invasion oral squamous carcinoma cells by modulating intracellular cAMP. Cancer Lett 176: 143-148, 2002. PMID: 11804741.

5 Al-Yahya M, Raish M, AlSaid MS, Ahmad A, Mothana RA, AlSohaibani M, Al-Dosari MS, Parvez MK and Rafatullah S: 'Ajwa' dates (Phoenix dactylifera L.) extract ameliorates isoproterenol-induced cardiomyopathy through downregulation of oxidative, inflammatory and apoptotic molecules in rodent model. Phytomedicine 23(11): 1240-1248, 2016. PMID: 26776662. DOI: 10.1016/j.phymed.2015.10.019

6 Eisenach JC, De Kock M and Klimscha W: alpha(2)-adrenergic agonists for regional anesthesia. A clinical review of clonidine (1984-1995). Anesthesiology 85(3): 655-674, 1996. PMID: 8853097.

7 Shankar P, Mueller A, Packiasabapathy S, Gasangwa D, Patxot M, O'Gara B, Shaefi S, Marcantonio ER and Subramaniam B: Dexmedetomidine and intravenous acetaminophen for the prevention of postoperative delirium following cardiac surgery (DEXACET trial): Protocol for a prospective randomized controlled trial. Trials 19(1): 326, 2018. PMID: 29929533. DOI: 10.1186/s13063-018-2718-0

8 Kim J, Kim S, Lee DW and Ryu DS: The alternative of oral sedation for pediatric dental care. Review. J Dent Anesth Pain Med 15(1): 1-4, 2015. PMID: 28879251.

9 Kishikawa H, Kobayashi K, Takemori K, Okabe T, Ito K and Sakamoto A: The effects of dexmedetomidine on human neutrophil apoptosis. Biomed Res 29: 189-194, 2008. PMID: 18724006.

10 Ma D, Hossain M and Rajakumaraswamy N: Dexmedetomidine produces its neuroprotective effect via the alpha 2Aadrenoceptor subtype. Eur J Pharmacol 502: 87-97, 2004. PMID: 15464093. DOI: 10.1016/j.ejphar.2004.08.044

11 Chang A, Yeung S, Thakkar A, Huang KM, Liu MM, Kanassatega RS, Parsa C, Orlando R, Jackson EK, Andresen BT and Huang Y: Prevention of skin carcinogenesis by the $\beta$-blocker carvedilol. Cancer Prev Res (Phila) 8(1): 27-36, 2015. PMID: 25367979. DOI: 10.1158/1940-6207.CAPR-14-0193

12 Kantoh K, Ono M, Nakamura Y, Nakamura Y, Hashimoto K, Sakagami $\mathrm{H}$ and Wakabayashi $\mathrm{H}$ : Hormetic and anti-radiation effects of tropolone-related compounds. In Vivo 24: 843-851, 2010. PMID: 21164042.

13 Otsuki S, Sugiyama K, Amano O, Yasui T and Sakagami H: Negative regulation of NaF-induced apoptosis by Bad-CAII complex. Toxicology 287: 131-136, 2011. PMID: 21708216. DOI: $10.1016 /$ j.tox.2011.06.007

14 Yanagisawa-Shiota F, Sakagami H, Kuribayashi N, Iida M, Sakagami T and Takeda M: Endonuclease activity and induction of DNA fragmentation in human myelogenous leukemic cell lines. Anticancer Res 15: 259-266, 1995. PMID: 7762992.

15 Sakagami H, Satoh K, Ida Y, Hosaka M, Arakawa H and Maeda $\mathrm{M}$ : Interaction between sodium ascorbate and dopamine. Free Radic Biol Med 25: 1013-1020, 1998. PMID: 9870554.
16 Niwa H, Sugimura M, Satoh Y and Tanimoto A: Cardiovascular response to epinephrine-containing local anesthesia in patients with cardiovascular disease. Oral Surg Oral Med Oral Pathol Oral Radiol 92(6): 610-616, 2001. PMID: 11740477.

17 Niwa H, Hirota Y, Sibutani T, Idohji Y, Hori T, Sugiyama K, Joh $\mathrm{S}$, Kuji A and Matsuura $\mathrm{H}$ : The effects of epinephrine and norepinephrine administered during local anesthesia on left ventricular diastolic function. Anesth Prog 38(6): 221-226, 1991. PMID: 1842160

18 Ozaki M Takeda J, Tanaka K, Shiokawa Y, Nishi S, Matsuda K, Doi M, Kakihana Y, Fujino Y, Takinami M and Kawai M: Safety and efficacy of dexmedetomidine for long-term sedation in critically ill patients. J Anesth 28(1): 38-50, 2014. PMID: 23912755. DOI: $10.1007 / \mathrm{s} 00540-013-1678-5$

19 Calabrese EJ: Paradigm lost, paradigm found: The re-emergence of hormesis as a fundamental dose-response model in the toxicological sciences. Environ Pollut 138: 379-412, 2005. PMID: 16098930. DOI: 10.1016/j.envpol.2004.10.001

20 Fujisawa S, Atsumi T, Kadoma Y and Sakagami H: Antioxidant and prooxidant action of eugenol-related compounds and their cytotoxicity "phenolic compounds: free mechanisms of toxicity, catalysis, and protection". Toxicology 177: 39-54, 2002. PMID: 12126794.

21 Ishihara M, Yokote Y and Sakagami H: Quantitative structurecytotoxicity relationship analysis of coumarin and its derivatives by semiempirical molecular-orbital method. Anticancer Res 26: 2883-2886, 2006. PMID: 16886609.

22 Fricker M, Tolkovsky AM, Borutaite V, Coleman M and Brown GC: Neuronal Cell Death. Physiol Rev 98(2): 813-880, 2018. PMID: 29488822. DOI: 10.1152/physrev.00011.2017

23 Huang TH, Ding SJ, Hsu TZ, Lee ZD and Kao CT: Root canal sealers induce cytotoxicity and necrosis. J Mater Sci Mater Med 15(7): 767-771, 2004. PMID: 15387412.

24 Frank D and Vince JE: Pyroptosis versus necroptosis: Similarities, differences, and crosstalk. Cell Death Differ 26(1): 99-114, 2019. PMID: 30341423. DOI: 10.1038/s41418-0180212-6

25 Zheng Jun Shang, Ke Liu and De Feng Liang: Expression of beta2-adrenergic receptor in oral squamous cell carcinoma. J Oral Pathol Med 38: 371-376, 2009. PMID: 19141064. DOI: 10.1111/j.1600-0714.2008.00691.x

26 Bernabé DG, Tamae AC, Biasoli ÉR and Oliveira SH: Stress hormones increase cell proliferation and regulate interleukin-6 secretion in human oral squamous cell carcinoma cells. Brain Behav Immun 25(3): 574-583, 2011. PMID: 21187140. DOI: 10.1016/j.bbi.2010.12.012
Received March 7, 2019

Revised March 19, 2019

Accepted March 21, 2019 